\title{
Culpa e Gozo, Psicanálise e Literatura
}

\author{
Sérgio Scotti ${ }^{1}$ \\ Universidade Federal de Santa Catarina
}

\begin{abstract}
Resumo
Neste artigo faz-se uma releitura do conhecido trabalho de Freud, Dostoyevski e o parricídio (1927), a partir da articulação que Lacan realiza sobre a culpa em seu Seminário V, As formações do inconsciente. A suposta epilepsia de que Dostoyevski seria acometido, é questionada por Freud que entende os "ataques" do escritor russo como resultado de uma identificação histérica com o pai morto. Implicada nesta interpretação, está a questão da culpa pelo assassinato do pai. Contudo, pode-se reler a interpretação freudiana a partir da formulação lacaniana de que, uma demanda de morte endereçada ao Outro implica na morte do próprio sujeito. Ao final do artigo discute-se a culpa na histeria e na obsessão, propondo-se também que a questão do estilo perpassa tanto a criação literária quanto o diagnóstico clínico.
\end{abstract}

Palavras-chave: Culpa; gozo; psicanálise; literatura.

Guilt and Enjoyment, Psychoanalysis and Literature

\begin{abstract}
In this article, a re-reading of the well-known work by Freud, Dostoyeuski and parricide (1927) is carried out, departing from the considerations about guilt made by Lacan in his Seminar V, The formations of the unconscious. The presumed epilepsy, of which Dostoyevski might have suffered, is questioned by Freud who understands the "attacks" of the Russian writer as a result of a hysterical identification with his dead father. In this interpretation, the issue of the guilt for the father's murder is implied. However, it is possible to re-read Freud's interpretation from Lacan's argument that a death claim addressed to the Other causes the death of the subject himself. The end of the article discusses guilt in hysteria and obsession, proposing, also, that the issue of style has to do with the literary creation as well as the clinical diagnosis.

Keywords: Guilt; enjoyment; psychoanalysis; literature.
\end{abstract}

Neste artigo pretende-se realizar uma releitura do conhecido trabalho de Freud (1928/1973), "Dostoyevski e o parricídio", a partir da articulação que realiza Lacan (1957-1958/1999) sobre a culpa, em seu Seminário V, "As formações do inconsciente".

No texto freudiano, encontramos a culpa inconsciente, pelo desejo de morte dirigido à figura paterna, como a causa dos acessos histeroepiléticos de Dostoyevski, interpretados como um auto-castigo que o literato impingia a si mesmo através de sua identificação ao pai morto. Ao mesmo tempo, através dessa identificação, encontrava a oportunidade de realização de seu desejo incestuoso. Aqui, onde a identificação tem a dupla função de auto-castigo e realização do desejo, encontramos a possibilidade de uma rearticulação da interpretação freudiana, entendendo-a a partir da formulação lacaniana de que a culpa reside numa demanda de morte que mata o desejo.

Em seu trabalho, Freud busca compreender a personalidade de Dostoyevski e especialmente, seus "ataques

\footnotetext{
${ }^{1}$ Endereço para correspondência: Departamento de Psicologia, CFH, UFSC, Campus Universitário, Trindade, 88040-900, Florianópolis, SC. Fone (48) 331 9283/9961 1011, Fax (48) 331 9984. E-mail: sscotti@mbox1.ufsc.br ${ }^{2}$ Especialmente no seu capítulo XXVIII, "Tu és aquele a quem odeias".
}

de morte" que eram considerados, por sua manifestação mais aparente, como ataques epilépticos - "graves ataques de convulsões musculares, acompanhados de perda de consciência, seguidos de profunda depressão" (Freud, 1928/ 1973, p. 3005). ${ }^{3}$ Nesse ponto, Freud faz distinção entre a epilepsia como um mal do cérebro e os ataques de Dostoyevski como manifestações histéricas. Se a epilepsia do escritor russo pudesse ser admitida, ela deveria ser classificada então, como "epilepsia afetiva" e não orgânica.

Os ataques do escritor são entendidos, então, como provenientes de identificação histérica com um morto, no caso, o próprio pai de Dostoyevski. Coisa fácil de se encaixar no conflito imaginário do Complexo de Édipo: "Quiseste matar teu pai para ocupar seu lugar. Pois bem: agora és o pai, mas o pai morto". (Freud, 1928/1973, pp. 3009-3010) ${ }^{4}$

A necessidade de castigo implícita na fórmula anterior, nos é dada por Freud, nesta obra, como resultante da ambivalência afetiva do menino Dostoyevski que, ao mesmo tempo, deseja a morte do pai, ama-o, e deseja ser amado por ele. Tal disposição "homossexual" (Freud, 1928/1973) revelava-se, na atitude carinhosa do escritor para com seus próprios rivais amorosos e na capacidade

\footnotetext{
3 a tradução é nossa.

4 idem.
} 
de compreensão de certas situações expressas em suas novelas que se explicariam por uma homossexualidade reprimida.

Mesmo antes de seus "ataques epilépticos" se agravarem, a conseqüência do assassinato do pai, Freud refere na biografia de Dostoyevski, toda uma sintomatologia dos anos precoces da infância do escritor, caracterizada pelo medo da morte, estados melancólicos repentinos e aparentemente imotivados, acompanhados de sono letárgico.

Temos todos os ingredientes, então, de uma neurose histérica grave com uma sintomatologia que acompanhavase de conseqüências sérias para a vida de Dostoyevski e para aqueles com quem se relacionava. Sua mulher viveu o drama de uma compulsão do marido ao jogo que por vezes levou-os à ruína, mas, que era, justamente, a condição para que o escritor tivesse seu melhor rendimento como literato. Sendo o mesmo o que acontecia quando de sua prisão na Sibéria que, apesar de injusta, era aceita, inconscientemente é claro, por Dostoyevski, como um castigo necessário (Freud, 1928/1973). Tanto que por essa época, segundo suposição de Freud - contrariando as suposições dos biógrafos e as próprias recordações de Dostoyevski - os ataques deveriam desaparecer, já que o castigo se atualizava pela própria condição de encarcerado.

A produção literária de Dostoyevski não se viu prejudicada por tais revezes da vida, pelo contrário, alimentava-se deles. O que se expressa no fato de uma predileção por temas em que o crime e o castigo andam juntos e em que a psicologia do criminoso, aparece traduzida em suas múltiplas facetas: o delinqüente egoísta, o criminoso político ou religioso e, finalmente, o parricida, criminoso propriamente humano e que marca a existência de todo sujeito (Freud, 1928/1973).

O fio que perpassa todo o drama da vida e da obra de Dostoyevski, é o sentimento de culpabilidade, expresso no conflito entre as instâncias psíquicas do eu e do supereu que, como herdeiro da identificação com o pai, mantém o eu, de forma masoquista, subjugado pela culpa e pela necessidade de castigo. Mas se a necessidade de castigo se mantém, e com ela a culpa, pensamos, sem muita dificuldade que, igualmente, mantêm-se também, o desejo de morte e a fantasia de se ocupar o lugar do pai junto à mãe, ou seja, mantém-se aí uma satisfação, um gozo. Se goza daquilo que se sofre (Lacan, 1973/ 1990) no sintoma.

Poderíamos nos contentar com esta articulação que é originalmente a de Freud (1926/1973), perfeitamente válida, tanto que é reconhecido por Lacan na forma de um gozo, aquilo que Freud já chamava de uma formação de compromisso, que se estabelece no sintoma, através do qual, apesar dos pesares, o neurótico se satisfaz, "Digamos que, por essa espécie de satisfação, eles se fazem sofrer demais." (Lacan, 1973/1990, p.158)
No entanto, gostaríamos de dar um passo a mais na compreensão da questão da culpa, especialmente referida ao caso de Dostoyevski, a partir de uma articulação proposta por Lacan (1957-1958/1999) a esse respeito, que em seu Seminário V, "As formações do inconsciente", trata da culpa presente na estrutura do obsessivo. Elabora seu ponto de vista a partir da crítica a um caso clínico relatado por Glover (1950, citado em Lacan, 1957-1958/1999) intitulado "Incidências terapêuticas na conscientização da inveja do pênis na neurose obsessiva" no qual identifica como questão fundamental da paciente o penisneid, ou seja, a inveja do pênis e a interpretação desse mesmo autor, de que o desejo da paciente fosse simplesmente o de ser um homem.

À parte essa simplificação, também critica a "cura" do caso que, segundo ele, restringiu-se a uma identificação com o próprio analista ou, mais especificamente, a uma absorção do falo do analista com a permissão deste, o que determinou, no melhor dos casos, a continuação das fantasias obsessivas, mas sem culpa.

Queres destruir meu falo de analista, diz o analista, e eu, de minha parte, o dou a ti. Em outras palavras, a análise inteira é concebida como o fato de que o analista doa fantasisticamente o falo, consente com um desejo de posse fálica. Ora, não é disso que se trata, e uma das provas que podemos dar é que, no ponto quase terminal a que parece ter sido levada a análise, é dito que a paciente conserva todas as suas obsessões, exceto pelo fato de que já não se angustia com elas. (Lacan, 1957-1958/ 1999, p. 467)

É de se compreender tal crítica, pois se é na relação ao Outro que a culpa se instala e se dele vem a permissão para que o sujeito se instale em seu lugar, resulta daí que o sujeito mantém em seu lugar o Outro ao mesmo tempo em que se identifica imaginariamente com ele às custas de seu próprio desejo o qual se mantém alienado no Outro. A prova disso é que os sintomas continuam, e mais ainda, segundo Lacan (1957-1958/1999), pelo fato de que a paciente traz à análise seu próprio filho, demonstrando assim, que algo ficou por se analisar.

O que faz a paciente? A observação o diz, com total ignorância: ela intervém com toda sua força junto ao filho mais velho, de quem sempre teve um medo pavoroso, porque, a bem da verdade, ele é o único cujas reações masculinas ela nunca conseguiu dominar, dizendo-lhe que ele mesmo precisa, com toda a urgência, fazer-se analisar. Que significa isso, se não que o falo que o analista acredita ser a solução da situação - na medida em que, ele mesmo assumindo a posição da mãe benevolente, entrega-o à paciente - ela o devolve? Um castigo merecido. (Lacan, p. 467) 
E o que ficou por se analisar, foi a dimensão simbólica representada pelo lugar que o sujeito ocupa em relação ao falo como significante do desejo. Na economia do obsessivo, o falo ocupa, inversamente, um lugar preponderante na constituição de seu desejo (Lacan, 1957-1958/1999).

$\mathrm{Na}$ medida em que o desejo vem do Outro, quando a mãe, por exemplo, espera encontrar no filho o falo, o que eqüivale a dizer que o falo vem do Outro que o deseja no filho, é na relação com esse Outro que o próprio sujeito se constitui. Vale lembrar que esse Outro como lugar da linguagem, é o lugar pelo qual deve passar necessariamente a demanda do sujeito humano (Lacan, 1957-1958/1999). Aí é que se constitui o desejo, aquela hiância entre o que se demanda e o que se visa, pois, o que se demanda através da linguagem é sempre algo que está além da linguagem, mas que somente pode ser vislumbrado por meio da própria linguagem. O Outro, então, é o lugar de onde advém o desejo, o desejo do próprio Outro é o que se visa na demanda, portanto toda demanda é demanda de amor.

A inserção do homem no desejo sexual está fadada a uma problemática especial, cujo traço primordial é que ela deve encontrar lugar em alguma coisa que a precede, que é a dialética da demanda, na medida em que a demanda sempre pede alguma coisa que é mais do que a satisfação a que ela apela, e que vai mais além disso. Daí o caráter problemático e ambíguo do lugar onde se situa o desejo. Esse lugar está sempre para além da demanda, considerando que a demanda almeja a satisfação da necessidade, e no aquém da demanda, na medida em que esta, por ser articulada em termos simbólicos, vai além de todas as satisfações para as quais apela, é demanda de amor que visa ao ser do Outro, que almeja obter do Outro uma presentificação essencial - que o Outro dê o que está além de qualquer satisfação possível, seu próprio ser, que é justamente o que é visado no amor. (Lacan, p. 418)

Poderíamos dizer que a demanda de amor é uma demanda por se ocupar o lugar do desejo do Outro, ou seja, o lugar do falo. No entanto, e isso é o que caracteriza a estrutura neurótica, há um outro falo que é desejado pelo Outro (materno), o falo rival que é o pai. Se se passa a não mais desejar ser o falo, mas sim, tê-lo sob um pano de fundo de não tê-lo, ou não tê-lo sob um pano de fundo de poder tê-lo, estaremos na possibilidade das identificações sexuais "normais" (Lacan, 1957-1958/1999). Contudo, na obsessão por exemplo, podemos ter a complicação de: por se evitar a castração, busca-se sê-lo, o falo, às custas da destruição do rival. O que passa também pelas disputas por quem tem ou não tem o falo como no caso da paciente anteriormente citada.

É nesta configuração que encontramos o desejo do obsessivo vinculado a uma demanda de morte do Outro.
Outro que se constitui, a partir da metáfora paterna, como Outro do Outro (a lei do pai no lugar do desejo da mãe) que, na verdade, é apenas um só lugar simbólico de onde se vislumbra o próprio desejo.

Mas então, se é do Outro que advém o próprio desejo do sujeito, uma demanda de morte endereçada a este Outro, significa a morte do próprio desejo.

É nisso que reside o dilema do obsessivo segundo Lacan (1957-1958/1999), é numa demanda de morte que se nega a si mesma que o obsessivo encontra a possibilidade de manutenção de seu próprio desejo. Daí advém a culpa, a ambivalência, a dúvida e toda a sintomatologia característica do obsessivo.

Noutras palavras, a morte ou destruição do Outro através de uma demanda de morte implica na morte do próprio sujeito. Deduz-se daí a importância que tem para o obsessivo a manutenção do Outro em seu lugar, tanto como garantia da manutenção de seu próprio lugar como sujeito, quanto forma de inserção de seu desejo que aparece, então, como forma de suplência ao desejo insatisfeito do Outro materno. A mãe do obsessivo, embora reconheça que o falo esteja do lado do pai, representa-o para o filho como insatisfatório (Dör, 1994).

A culpa aparece, então, como corolário estrutural que se mostra como signo de um gozo, que se mantém na oscilação mesma entre ser o falo para o Outro e o desaparecimento do sujeito como sujeito do desejo, o que é evitado por medidas restauradoras que buscam recolocar o Outro em seu devido lugar através de expedientes defensivos como a denegação, a anulação, o isolamento.

Mas estávamos a falar de Dostoyevski, um histérico segundo Freud (1928/1972). Poderíamos atribuir a mesma concepção de culpa que Lacan (1957-1958/1999) desenvolve a respeito da estrutura obsessiva, ao sintoma do escritor russo?

A culpa não é privilégio do obsessivo, bem sabemos, encontramo-la, como podemos ver a partir do exemplo de Freud, no histérico também. Cabe perguntar se essa experiência da culpa configura-se no sujeito histérico, a partir da mesma dialética estrutural.

Se histeria e obsessão são estruturalmente diferentes e ao mesmo tempo semelhantes, deveremos poder encontrar as semelhanças e diferenças entre elas quanto à culpa.

Como vimos nos parágrafos anteriores em que abordamos a relação do sujeito com o lugar do Outro, primeiro como Outro materno, depois como Outro da lei, no obsessivo a culpa se alimenta de um movimento de oscilação permanente entre amor e ódio, entre a edificação do Outro como lugar desejado e, ao mesmo tempo, temido desde que dele pode advir o próprio desaparecimento do desejo. Os temores fantasiosos, ao nível 
imaginário, das medidas retaliativas do Outro, devem ser referidas a esse desaparecimento do desejo.

Ainda uma outra coisa marca a culpa do obsessivo, é que ela se estrutura fundamentalmente em torno de significantes. Seja através da blasfêmia compulsiva, ou seja através das auto-recriminações ou dos temores em fazer mal a alguém, veja-se "O Homem dos Ratos" (Freud, 1909/ 1972) é em torno de pensamentos que gira a culpa do obsessivo, em torno de uma cadeia significante em que, ao mesmo tempo que o Outro é atacado, ele é reafirmado como lugar do significante.

Quanto à histeria, como vemos em Dostoyevski, a culpa, estruturalmente falando, deve-se à mesma dialética entre o lugar do Outro e o lugar do sujeito. Quando o sujeito Dostoyevski - se assim podemos denominá-lo em sua fantasia, coloca-se no lugar do Outro destruindoo, é ele mesmo que acaba por se destruir. Mas é aqui que encontramos a diferença que marca a culpa do histérico em relação ao obsessivo. Enquanto no obsessivo predominam os pensamentos em torno dos quais o sujeito goza de forma sadomasoquista, no histérico é na angústia e no próprio corpo que se goza. Isso não quer dizer que a culpa do histérico não se articule em torno de significantes. Na histeria o corpo torna-se significante.

Através da identificação histérica, o desfalecimento do Outro reverte-se em desfalecimento do próprio corpo, ou na angústia de um desfalecimento iminente. Desfalecimento de um significante que é o próprio falo marcado por sua detumescência que eqüivale à castração simbólica.

É interessante notar que é especialmente após a ruína e durante a prisão, como em outros momentos castrativos de sua vida, que Dostoyevski tem seus maiores rendimentos literários.

Não é difícil ver aí o fato de que, ao liberar-se do gozo da culpa, desabrocha em Dostoyevski uma produção significante em que, o desejo corre solto na pena do escritor através de uma cadeia significante em que, como bem notou Freud, vemos a marca de um processo identificatório histérico com o criminoso. Criminoso que embora castigado ou, até mesmo por isso, é idealizado, é mostrado como um herói, um herói do sofrimento e da culpa que vai encontrar seu limite, sua castração, no castigo que, ao mesmo tempo, é sua libertação.

Também não é difícil ver aqui outra marca da histeria na qual o escritor busca, no algoz, um mestre que possa dizer-lhe como goza A mulher. A mulher (com maiúscula) que não existe segundo Lacan (1975/1985) e o mistério de seu gozo, é o que impulsa o/a histérico/a a identificar-se com o homem ou a mulher segundo o caso. Conforme a penetrante análise de Freud, esta é uma das facetas do complexo de Édipo de Dostoyevski no qual o mesmo vem a identificar-se numa posição feminina em relação ao pai, ou seja, em relação ao Outro/algoz que nunca é satisfatório o suficiente para impedi-lo de vislumbrar a Coisa, a mãe completa e sem falha que só é mesmo possível de se vislumbrar pela falha do pai/algoz em proibi-la.

Por outro lado, a culpa de Dostoyevski, e sua conseqüente necessidade de auto-castigo, sublinhada por Freud, nos leva a pensar que haveria por parte do sujeito culpado, uma certa apreensão da lei, e que sua transgressão na fantasia, é o que determinaria o castigo necessário.

Mas o que nos propõe Lacan é que “... não há necessidade alguma de qualquer referência a Deus nem à lei para que o homem fique literalmente imerso na culpa." (Lacan, 1957-1958/1999, p. 510)

Mais adiante, Lacan (1957-1958/1999) aponta que

... em se tratando da demanda de morte, evidentemente, é o Não matarás que se perfila no horizonte e constitui o drama. Mas o castigo não retira seu impacto daquilo que surge nesse lugar como resposta. É que, por razões que se prendem à estrutura do Outro para o homem, a demanda de morte é equivalente à morte da demanda. (p. 510)

Noutras palavras, diríamos que os ataques de morte do autor de "Os irmãos Karamazov", são uma ilustração exemplar do que nos diz Lacan. Quando Dostoyevski demanda a morte do Outro, na figura de seu pai, é a si próprio que ele mata, confirmando assim, o adágio contido no título da última aula do Seminário V de Lacan (19571958/1999): “Tu és aquele a quem odeias" (p. 504).

A outra saída para o sujeito indicada por Lacan, e é nesta direção que a análise deve levá-lo, é perceber que ele não é o falo e, portanto, “....aceitar tê-lo, quando ele o tem, e não tê-lo, quando não o tem" (Lacan, 1957-1958/1999, p. 499).

Essa saída, é uma outra saída que não pelo sintoma, que é o preço que o sujeito paga quando não abre mão de seu gozo, mesmo que seja um gozo culpado.

O gozo, então, é o que prende o sujeito ao seu sintoma. Antiga lição de Freud que deve nos orientar na clínica, quando nos perguntamos sobre as razões do sofrimento do paciente. O que é que se satisfaz no sujeito que sofre?

A resposta a essa pergunta pode ser a chave, por exemplo, da pulsão que está em jogo, ou do fantasma subjacente. A cura orienta-se, então, para uma perda de gozo, a perda do gozo de ser. Deixar de ser o falo para tê-lo ou não tê-lo, traz a questão da castração que é o que se quer evitar na neurose, como nas outras estruturas.

A consideração de como se evita a castração e/ou se mantém o gozo no sintoma, é fundamental na questão do diagnóstico e no manejo da transferência. Em cada estrutura, e é justamente isso que faz de cada estrutura o que ela é, 
a estratégia que o sujeito adota para evitar a castração e manter o gozo, é que vai configurar seu desejo como um desejo histérico ou obsessivo, ou se esse desejo vai ser subsumido numa negação da castração, tal como acontece nas perversões, ou ainda, no caso das psicoses, se esse desejo nem chega a constituir-se por força da forclusão.

Mas isso tudo é geral, são fatos de estrutura em que o histérico deseja um desejo insatisfeito, ou o obsessivo, um desejo impossível (Lacan, 1957-1958/1999). O que realmente importa é saber como cada sujeito desenvolve sua própria estratégia, qual o seu estilo. É por isso que na clínica psicanalítica se deixa, se pede, se espera que o sujeito fale. Até porque é próprio do sujeito que ele tenha seu estilo quando fala, na transferência.

E é o estilo de Dostoyevski que nos dá alguma luz sobre como funciona a estrutura. Assim, a literatura ensina à psicanálise.
Freud, S. (1973). Analisis de un caso de neurosis obsesiva: Caso el Hombre de las Ratas. (L. L. B. Torres, Trad.). Em J. N. Tognola (Org.), Obras Completas de Sigmund Freud (Vol. 2, pp. 1441 - 1486). Madrid: Biblioteca Nueva. (Original publicado em 1909)

Freud, S. (1973). Inhibicion, sintoma y angustia. (L. L. B. Torres, Trad.). Em J. N. Tognola (Org.), Obras Completas de Sigmund Freud (Vol. 3, pp. 2834 2883). Madrid: Biblioteca Nueva. (Original publicado em 1926)

Freud, S. (1973). Dostoyevski y el parricidio. (L. L. B. Torres, Trad.). Em J. N. Tognola (Org.), Obras Completas de Sigmund Freud (Vol. 3, pp. 3001 3015). Madrid: Biblioteca Nueva. (Original publicado em 1928)

Lacan, J. (1985) O Seminário: livro 20: Mais, ainda. Texto estabelecido por Jacques Alain Miller, versão brasileira de M. D. Magno. Rio de Janeiro: Jorge Zahar Editor. (Original publicado em 1975)

Lacan, J. (1990) O Seminário: livro 11: Os quatro conceitos fundamentais da psicanálise. Texto estabelecido por Jacques Alain Miller(M. D. Magno, Trad.). Rio de Janeiro: Jorge Zahar Editor. (Original publicado em 1973)

Lacan, J. (1999) O Seminário: livro 5: As formações do inconsciente. Texto estabelecido por Jacques-Alain Miller, (V. Ribeiro, Trad.). Rio de Janeiro: Jorge Zahar Editor. (Original publicado em 1998)

\section{Referências}

Dör, J. (1994). Estruturas e clínica psicanalítica. Rio de Janeiro: Taurus.

Sobre o autor

Sérgio Scotti é Psicanalista, Doutor em Psicologia Clínica pela USP com a tese "A Estrutura da Histeria em Madame Bovary". Atualmente é Professor adjunto do Departamento de Psicologia da Universidade Federal de Santa Catarina. 


\section{MESTRADO E DOUTORADO EM PSICOLOGIA DO DESENVOLVIMENTO}

2003

S

Se você é graduado em Psicologia, tem um bom domínio da língua inglesa e deseja se preparar para ser um pesquisador, professor universitário, ou mesmo um profissional de alta qualificação, o Programa de Pós-Graduação em Psicologia do Desenvolvimento da Universidade Federal do Rio Grande do Sul é o local que você procura. Desfrute de um ambiente acadêmico estimulante, onde alunos e professores convivem diariamente, com dedicação integral ao estudo e à pesquisa. Escreva-nos pedindo maiores informações.

INFORMAÇÕESE INSCRIÇÃO

\section{UFRGS}

UNIVERSIDADE FEDERAL

DO RIO GRANDE DO SUL

Instituto de Psicologia

PROGRAMA DE PÓS-GRADUAÇÃO EM PSICOLOGIA DO DESENVOLVIMENTO

Secretaria do PPG em Psicologia do Desenvolvimento - UFRGS

Rua Ramiro Barcelos, 2600 Sala 110 Campus da Saúde

90035-003 Porto Alegre RS Brasil

Fone: (51) 33165246 Fax: (51) 33309507

http://urso.psico.ufrgs.br/ppg

http://www.psicologia.ufrgs.br/pos_psico 